\title{
Análise do Uso, Cobertura e Manejo da Terra e sua influência no Transporte de Sedimentos em Suspensão na Bacia Hidrográfica do Córrego Moeda, Três Lagoas/MS
}

Analysis of the Use, Coverage and Land Stewardship and its influence on Sediment Transport in suspension in the Hydrographic Basin of Stream Moeda, Três Lagoas/MS

Análisis del Use, la Cubierta y Manejo de la Tierra y su influencia en Transporte de

Sedimentos en Suspensión en la Cuenca Hidrográfica del Arroyo Moeda, Três Lagoas/MS

Rafael Brugnolli Medeiros Doutorando em Geografia pela Universidade Federal da Grande Dourados, UFGD, Brasil rafael_bmedeiros@hotmail.com

André Luiz Pinto Professor Adjunto IV da Universidade Federal de Mato Grosso do Sul, UFMS, Brasil. andre.pinto@ufms.br

Angélica Estigarribia São Miguel Mestrando em Geografia pela Universidade Federal de Mato Grosso do Sul, UFMS, Brasil weslenmanari@hotmail.com 


\section{RESUMO}

O objetivo desta pesquisa é analisar o uso, cobertura e manejo da terra e sua influência no transporte de sedimentos em suspensão da Bacia Hidrográfica do Córrego Moeda - BHCM, localizada no município de Três Lagoas, no estado de Mato Grosso do Sul. Os procedimentos metodológicos para a vazão e transporte de sedimentos em suspensão consiste na análise em 11 pontos de coleta das águas ao longo de toda a bacia. Já o mapeamento do uso, cobertura e manejo da terra foi realizado por meio dos softwares ArcGis $10^{\circledR}$ e Spring 5.2.6 ${ }^{\circledR}$, através das imagens Landsat 8/OLI do ano de 2014. Os resultados apontam que grande parte das terras da BHCM estão sendo utilizadas para plantio de eucalipto comercial, chegando a mais de $50 \%$ do total, levando em conta que as mesmas, possuem um manejo da terra e não adentram às áreas de preservação permanente. As pastagens, em grande maioria não possuem qualquer tipo de manejo, mostrando ser fator prejudicial ao transporte de sedimentos em suspensão, sobretudo no ponto 1, onde foi constatada uma alta sedimentação em uma área sem proteção de vegetação. Outros pontos a serem destacados pelos altos valores no transporte de sedimentos, são os pontos 7, 9, 10 e 11, que devido à sua vazão elevada e ao corte de talhões em grandes áreas próximas, acabaram elevando a quantidade de sedimentos transportados. Portanto, devido aos constantes cortes de talhões, é necessária que ocorra a continuação do monitoramento dos recursos desta bacia hidrográfica.

PALAVRAS-CHAVE: Bacia Hidrográfica. Transporte de Sedimentos em Suspensão. Uso, cobertura e Manejo da Terra. Vazão das Águas.

\section{SUMMARY}

The objective of this research is to analyze the use, coverage and land management and its influence on sediment transport in suspension of the Hydrographic Basin Currency Moeda -. BHCM located in the municipality of Três Lagoas, in the state of Mato Grosso do Sul. The methodological procedures for flow and sediment transport in suspension is the analysis of 11 water collection points throughout the basin. Already use mapping, cover and land management was conducted through ArcGis $10^{\circledast}$ and Spring 5.2. $6^{\circledR}$ software, through images Landsat 8 / OLI of 2014. The results show that most BHCM the land is being used for commercial eucalyptus plantation, reaching more than $50 \%$ of the total, taking into account that they possess a land management and not step into the areas of permanent preservation. Pastures in vast majority do not have any type of management, proving to be detrimental factor for the transport of suspended sediment, especially in paragraph 1, where a high sedimentation in an area without vegetation protection was found. Other points to be featured by high values of sediment transport, are the points 7, 9, 10 and 11, which owing to its high flow and shear plots in large areas close, just increasing the amount of sludge transported. Therefore, due to the constant plots of cuts, it is necessary to occur the continued monitoring of the resources of this hydrographic basin.

KEYWORDS: Hydrographic Basin. Sediment transport in suspension. Use cover and Land Stewardship. Flow of water.

\section{RESUMEN}

El objetivo de esta investigación es analizar el uso, la cobertura y manejo de la tierra y su influencia en el transporte de sedimentos en suspensión de la Cuenca Hidrográfica Arroyo Moeda - BHCM, situada en el municipio de Três Lagoas, en el estado de Mato Grosso do Sul. Los procedimientos metodológicos para el transporte y el flujo de sedimentos en suspensión se el análisis en 11 puntos de colecta de agua en toda la cuenca. Ya el mapeo del uso, la cobertura y manejo de la tierra se realiza a través del softwares ArcGis $10^{\circledR}$ and Spring 5.2.6 ${ }^{\circledR}$, por medio de imágenes Landsat 8 / OLI de 2014. Los resultados muestran que la mayor parte BHCM la tierra está siendo utilizado para la plantación de eucalipto comercial, llegando a más de $50 \%$ del total, teniendo en cuenta que poseen un manejo de la tierra y no caminan en las áreas de preservación permanente. Pastos en gran mayoría no tienen ningún tipo de gestión, demostrando ser el factor perjudicial para el transporte de sedimentos en suspensión, especialmente en el apartado 1, en donde se encontró una alta sedimentación en un espacio sin protección de la vegetación. Otros puntos de a tener en cuenta los valores altos en el transporte de sedimentos, son las puntos 7, 9, 10 y 11 , que debido a su alto flujo y corte de grandes parcelas en zonas cercanas, acabaram el aumento de la cantidad de sedimentos transportados. Por lo tanto, debido a los constantes cortes de lotes, es necesario que se produzca la supervisión continua de los recursos de esta cuenca.

PALABRAS CLAVE: Cuenca Hidrográfica. Transporte de sedimentos en suspensión. Uso, la Cubierta y Manejo de La Tierra. Flujo de Agua. 


\section{INTRODUÇÃO}

Esta pesquisa tem como unidade de estudo, a bacia hidrográfica do córrego Moeda - BHCM, localizada no município de Três Lagoas, no estado de Mato Grosso do Sul. Na região da BHCM, desde o período da ocupação até a década de 1980, ocorreram pequenas modificações em suas vegetações, visto que a atividade produtiva sempre esteve relacionada com a pecuária extensiva para criação de gado. A atividade de agricultura, a princípio, foi destinada à manutenção das fazendas; no entanto, a utilização do solo sem um adequado manejo, por longos anos, acarretou em processos evolutivos de degradação.

Segundo informações obtidas por meio do IBGE (s.d) a partir das décadas de 80 e 90 do século passado, as mudanças no município tomaram impulsos, com avanços na modernização das fazendas de gado e introdução de hortos florestais de eucaliptos, iniciada pela expectativa da vinda de indústrias de papel e celulose. Em decorrência destas alterações inicia-se uma modificação do uso, cobertura e manejo da terra da BHCM, porém ainda com pouca expressividade.

Com isso, a partir de 2006, as alterações tem sido marcantes nesta bacia hidrográfica pelo relativo aumento deste cultivo de eucalipto, estimulado pela vinda das indústrias de papel e celulose, mais precisamente da Fibria MS Celulose Ltda.

Atualmente, o estado de Mato Grosso do Sul é um dos maiores produtores de celulose do Brasil, e dados da Associação Sul-Mato-Grossense de Produtores e Consumidores de Florestas Plantadas (REFLORE - MS) apontam que nos últimos seis anos a área destinada ao cultivo do eucalipto no Estado cresceu 475\%. A expansão foi motivada, principalmente, pela instalação de duas indústrias de celulose na região leste de Mato Grosso do Sul. São aproximadamente 750 mil hectares destinados ao cultivo de eucalipto no Estado.

As plantações de eucalipto para a produção de celulose e papel na BHCM, estão distribuídas em 28 hortos florestais, com 625 talhões e idade média em torno dos 5 anos. Todas as florestas de eucalipto presentes na área pertencem à Fibria MS Celulose Ltda., e segundo informações disponibilizadas pela empresa Fibria MS Celulose Ltda, essas florestas de eucalipto são formadas predominantemente por híbridos de eucalipto obtidos a partir do cruzamento entre as espécies Eucalyptus grandis e Eucalyptus urophylla, ou cruzamentos manipulados geneticamente, que após vários ciclos de melhorias e pesquisas, estas foram selecionadas por melhor se adaptarem às condições locais, sendo que as atividades de plantio sempre priorizam a mínima utilização de recursos naturais e de insumos.

Outro agravante aos recursos hídricos da BHCM foi a instalação do Distrito Industrial do Moeda, criado pela Lei Municipal 2.427, de 2 de março de 2010, com principal finalidade de alojar grandes indústrias, como é o caso da fábrica Fibria MS Celulose Ltda. e da Unidade de Fertilizantes e Nitrogenados de Três Lagoas - UFN 3, de propriedade da Petrobras, uma das maiores fábricas de fertilizantes nitrogenados da America Latina, segundo o Relatório de Impacto Ambiental do Distrito Industrial.

Nestes locais é essencial a análise do uso, cobertura e manejo da terra, bem como toda a dinâmica deste ecossistema que, por sua vez, influencia diretamente nos processos de 
lixiviação, erosão, deslizamentos e modificações nos regimes hidrológicos que podem elevar o escoamento superficial/subterrâneo, definindo diversos parâmetros de resistência às ações dos agentes externos que interferem na quantidade e qualidade das águas, desencadeando um potencial erosivo extremamente alto, influenciando na sua velocidade, vazão e capacidade de dissecação, transporte e deposição de sedimentos.

A BHCM localiza-se no município de Três Lagoas/MS, situada na margem direita do Rio Paraná, portanto, a BHCM é considerada um subsistema do sistema Bacia Hidrográfica do Rio Paraná, possuindo uma área de $247,64 \mathrm{~km}^{2}$ e posiciona-se entre as coordenadas UTM de 393200 e 425000 metros Oeste e 7676692 e 7696172 metros Sul, Figura 1.

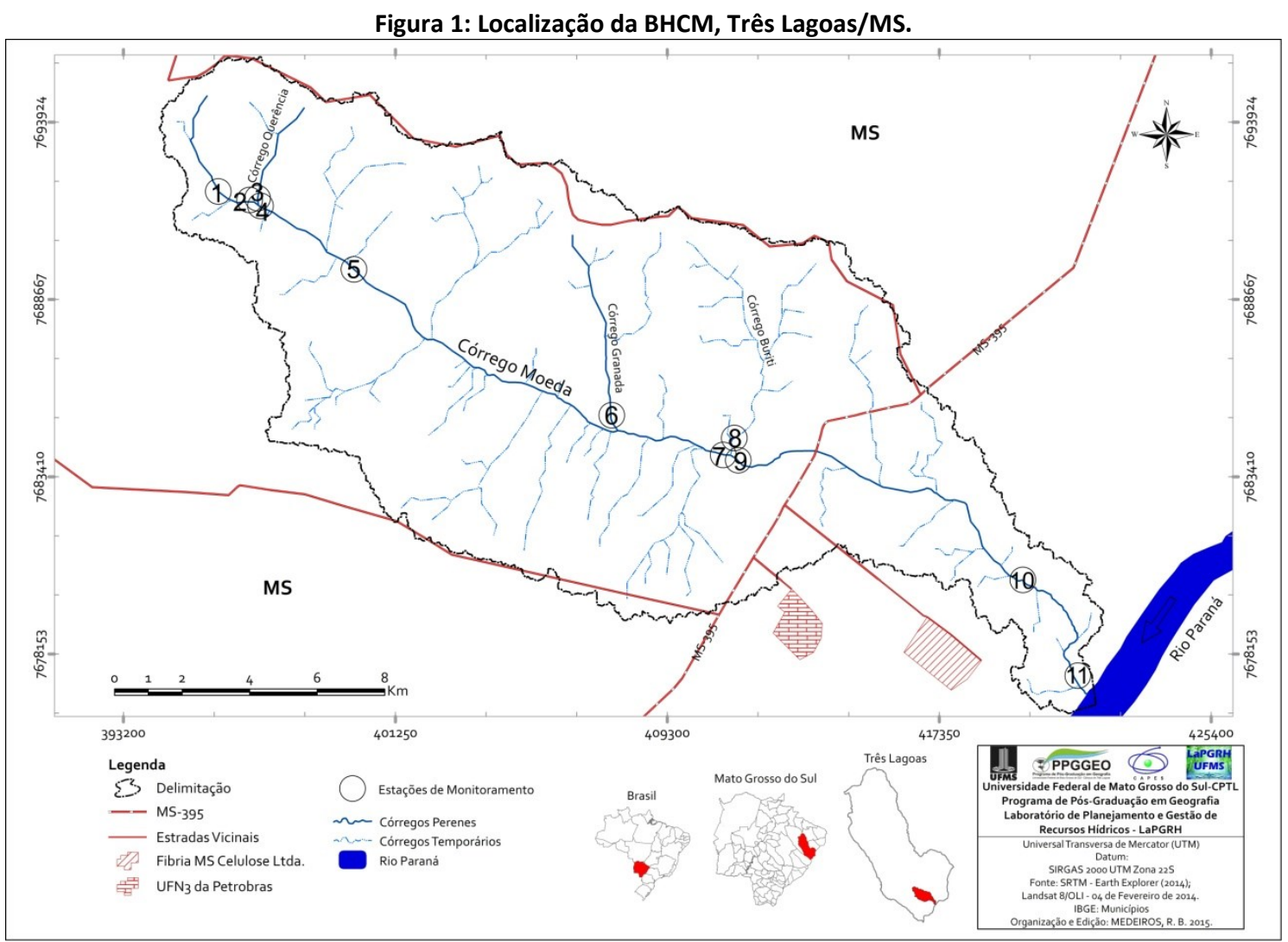

\section{OBJETIVOS}

O objetivo desta pesquisa consiste na análise do transporte de sedimentos em suspensão, buscando uma interação com o uso, cobertura de manejo da terra da Bacia Hidrográfica do Córrego Moeda, visto que, esta área possui grande parte de suas terras voltadas para o plantio de eucalipto, ocasionando alterações, sobretudo, em locais que ocorrem cortes de talhões. 


\section{METODOLOGIA}

No mapeamento do uso, cobertura e manejo da terra, é indispensável o emprego do geoprocessamento, que neste caso, optou-se por utilizar os SIG's ArcGis $10^{\circledR}$ (fabricante ESRI) e Spring 5.2.6 ${ }^{\circledR}$, (fornecido pelo INPE - Instituto Nacional de Pesquisas Espaciais).

O mapeamento da BHCM por meio da utilização de imagens de satélite Landsat 8, já georreferenciadas, foi realizado com as imagens Landsat 8/OLI, adquiridas gratuitamente no site da USGS, sendo realizados todos os procedimentos necessários para a classificação destas imagens, mapeamento de acordo com as saídas de campo e estas imagens utilizadas, sendo encontradas oito classes: Cerrado; Cerrado Úmido; Cultivo de Eucalipto; Cultivo de Seringueira; Edificações; Florestal; Pastagem; Solo Exposto. Buscando aplicar cores temáticas que auxiliem na identificação das classes nos mapas elaborados.

Juntamente com a evolução do uso, cobertura da terra na BHCM, foi realizada a classificação dos locais em que é possível identificar a presença de manejo da terra, que auxilia na conservação deste ecossistema. As classes de manejo da terra encontradas na BHCM foram Manejo de Pastagem Cultivada e Animal; Manejo de Eucalipto Comercial; Manejo de Solo Exposto para Eucalipto Comercial; Manejo de Hevea Brasiliensis,.

A análise da velocidade de fluxo, vazão e transporte de sedimentos em suspensão da BHCM, baseou-se na coleta de sedimentos em suspensão, bem como a vazão e velocidade dos canais fluviais. Estas coletas foram realizadas durante de 2014. Os locais da coleta foram enumerados do ponto 1 até o ponto 11 e foram selecionados antecipadamente segundo critérios como: açude, captação de água pela Fibria MS Celulose Ltda.; montante, foz dos afluentes e jusante dos três principais córregos tributários (Querência, Granada e Buriti) e próximo da foz do próprio Córrego Moeda.

A vazão consiste no cálculo da área da cada estação de coleta, de acordo com as metodologias de Christofoletti (1980); Pinto (1985) e Pinto et. al. (2010), onde a área é mensurada por meio da elaboração de perfil transversal, com espaçamento de $10 \mathrm{em} 10 \mathrm{~cm}$, que depois de elaborado em ambiente AutoCAD 2012, calculou-se a área da seção do canal, em m2. Após este procedimento, os valores alcançados de área em $\mathrm{m}^{2}$ é multiplicado pelos valores $\mathrm{da}$ velocidade de fluxo, produzindo assim, os dados de vazão.

Na mensuração do transporte de sedimentos em suspensão é realizada a coleta de amostras das águas superficiais ao longo dos mesmo onze pontos estabelecidos na BHCM. A carga de sedimento em suspensão pelos cursos fluviais é obtida pela ação erosiva que as águas desempenham sobre a bacia hidrográfica e o fundo dos leitos, especialmente.

Os frascos plásticos foram introduzidos nas áreas de maior velocidade do canal, até o fundo, sem que este se afunda no leito arenoso, para receber o fluxo de fundo com sedimentos em suspensão (PINTO et. al., 2009).

Para a mensuração utilizou-se das metodologias descritas por Christofoletti (1980); Pinto (1985); Pinto et. al. (2009) e Carvalho et. al. (2000), que consiste na análise em laboratório, onde os frascos foram agitados e colocados, $100 \mathrm{ml}$, em conjunto de infiltração da milipore, com filtro de 4,7 microns de celulose, que em seguida foram à estufa de secagem por 24 horas 
a 60ㄷ. Logo após resfriarem os filtros foram pesados em balança de precisão e compará-los com o peso de seus respectivos filtros sem sedimentos, como os valores correspondem a 100 $\mathrm{ml}$, estes foram convertidos para $\mathrm{m} 3$ e calculados os valores conforme as vazões mensuradas.

\section{RESULTADOS}

$\mathrm{Na}$ análise do uso, cobertura e manejo da terra na BHCM, foram constatados, por meio da Figura 2, alguns cortes de talhões nas proximidades da rodovia MS-395, no horto chamado Dobrão, bem como, próximo ao ponto 10 e 11. É importante a constatação do local em que foi realizado o corte dos talhões, pois influencia nas demais análises feitas, por ter a capacidade de aumentar o escoamento superficial, consequentemente, eleva o transporte de sedimentos em suspensão.

Figura 2: Mapa de uso, cobertura e manejo da terra da BHCM.

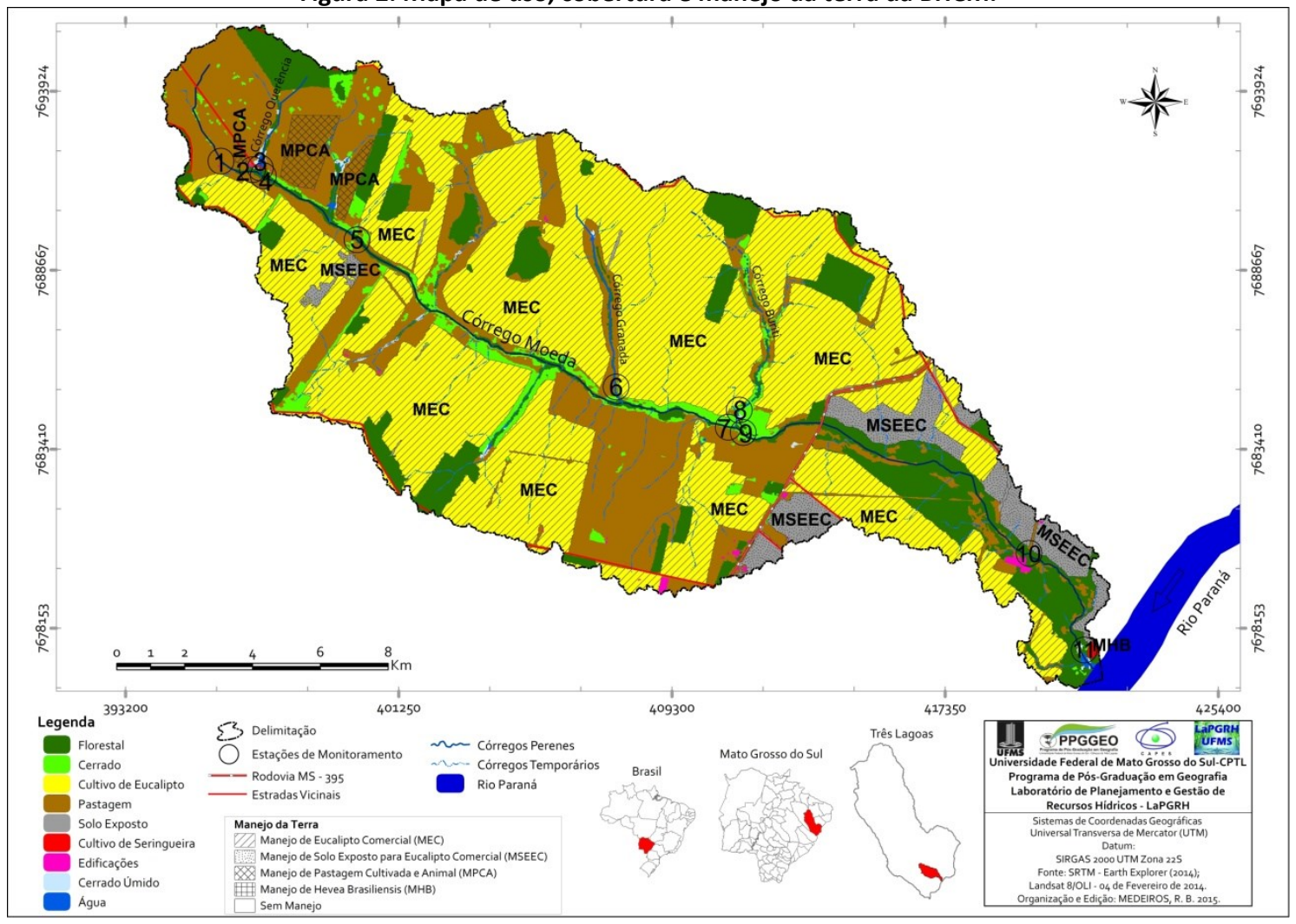

Na Tabela 1 e Figura 3, são demonstrados os valores que cada classe temática de uso, cobertura e manejo da terra abrange na BHCM, visualizando assim, as possíveis relações destas informações com as demais análises realizadas durante a pesquisa. 
Tabela 1: Classes de uso, cobertura e manejo da terra da BHCM.

\begin{tabular}{lcccc}
\hline & \multicolumn{2}{c}{ Uso e Cobertura da Terra } & \multicolumn{2}{c}{ Manejo da Terra } \\
& $\begin{array}{c}\text { Área } \\
\mathbf{( k m}^{\mathbf{2}}\end{array}$ & $\begin{array}{c}\text { Área } \\
(\mathbf{\%})\end{array}$ & $\begin{array}{c}\text { Área } \\
\mathbf{( k m}^{\mathbf{2}}\end{array}$ & $\begin{array}{c}\text { Área } \\
(\%)\end{array}$ \\
\hline Água & 1,44 & 0,59 & 0,00 & 0,00 \\
Cerrado & 8,48 & 3,42 & 0,00 & 0,00 \\
Cerrado Úmido & 1,46 & 0,59 & 0,00 & 0,00 \\
Cultivo de Eucalipto & 126,51 & 51,09 & 126,51 & 51,09 \\
Cultivo de Seringueira & 0,13 & 0,05 & 0,13 & 0,05 \\
Edificações & 1,18 & 0,48 & 0,00 & 0,00 \\
Florestal & 33,84 & 13,66 & 0,00 & 0,00 \\
Pastagem & 61,59 & 24,87 & 3,55 & 1,43 \\
Solo Exposto & 13,01 & 5,25 & 12,07 & 4,87 \\
\hline Total & 247,64 & 100,00 & 142,26 & 57,44 \\
\hline
\end{tabular}

Figura 3: Uso, cobertura e manejo da terra da BHCM.

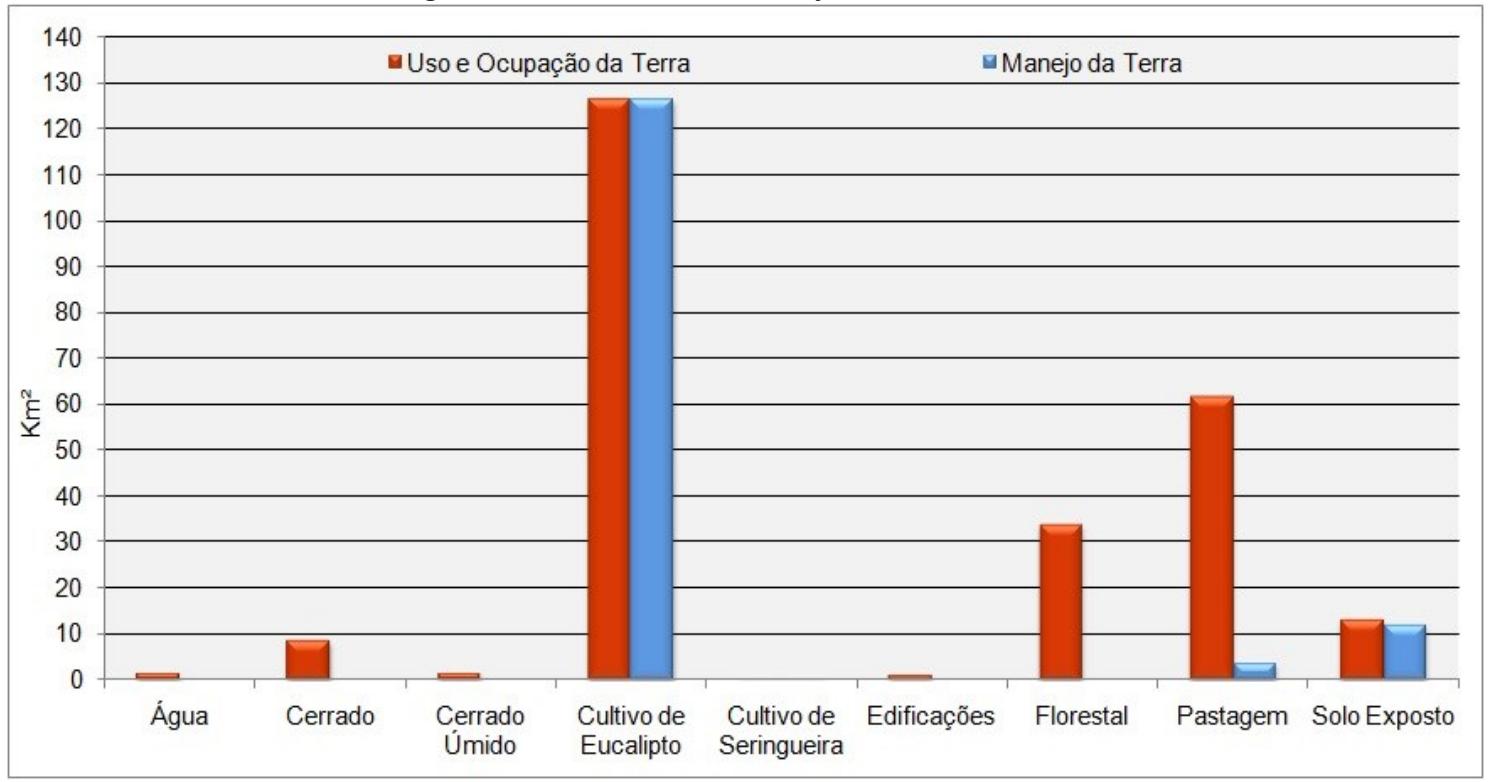

Nota-se que as áreas destinadas ao Cultivo de Eucalipto abrangeram $126,51 \mathrm{~km}^{2}$, que corresponde a 51,09\%, todas as áreas possuem Manejo de Eucalipto Comercial (MEC) e são de propriedade da Fibria-MS Celulose Ltda; sendo terrenos com curvas de nível e com realização de espaçamento das linhas de plantio, bem como, a implantação de caixas de retenção, fazendo a água escoar para as caixas, reduzindo o escoamento e possíveis ações erosivas.

A segunda classe que mais foi encontrada na BHCM, foi Pastagem, que abrangeu $61,59 \mathrm{~km}^{2}$ ou $24,87 \%$ do total da área, sendo encontrada no alto curso e também no médio curso, em toda a margem direta nos pontos 7 e 9 . Esta classe ficou caracterizada por grande parte de suas terras não apresentarem manejo, apenas na fazenda Querência, Figura 4, que foi constatado Manejo de Pastagem Cultivada e Animal (MPCA), na qual é realizado rodízio de pastagens com os animais, preservando os piquetes em todas as épocas do ano, entretanto, as áreas que abrangem este tipo de manejo alcançaram apenas $3,55 \mathrm{~km}^{2}$. 
Figura 4: Alto curso da BHCM, pastagem não manejada, esquerda, e pastagem manejada, direita, na fazenda querência.

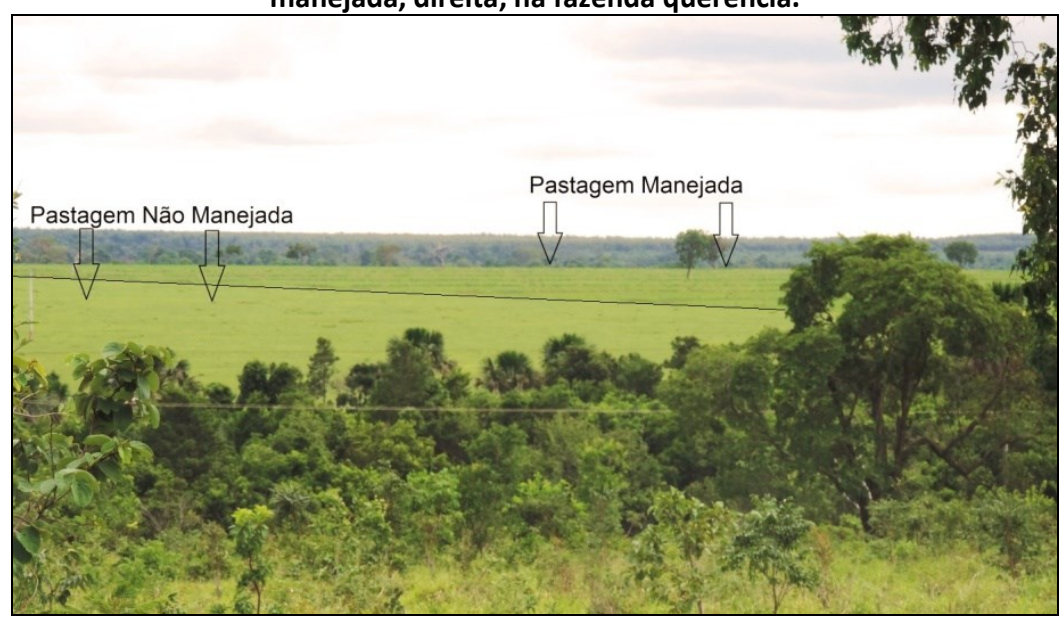

Outra classe que abrangeu áreas relevantes na BHCM foi Florestal, não possuindo manejo em suas terras e são caracterizadas desde mata ciliar até áreas de reserva legal, Figura 5, ao longo de toda a bacia hidrográfica, compreendendo $33,84 \mathrm{~km}^{2}$ ou $13,66 \%$ do total. Esta classe é representada pelo equilíbrio em seu ecossistema, apresentando vegetações que recobrem o solo e diminuem os efeitos de ventos e escoamento superficial.

Figura 5: Alto curso da BHCM, áreas de reserva legal, próximo ao limite da bacia, recoberta pela classe Florestal.

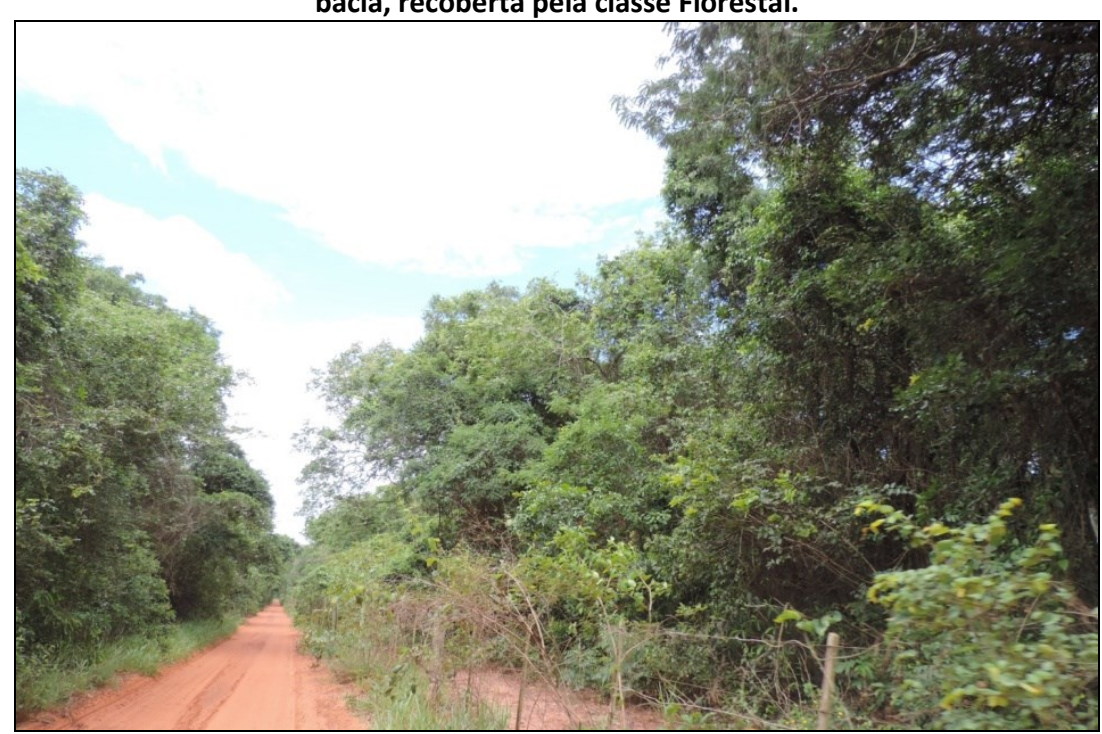

A Classe Água é peculiar na análise do uso, cobertura e manejo da terra, pois, o topo das árvores próximas (mata ciliar) acaba encobrindo sua real abrangência dentro da BHCM, ocasionando a distorção dos valores, entretanto, as áreas de Água, que foi possível sua classificação, aponta $1,44 \mathrm{~km}^{2}$ ou $0,59 \%$ do total. Esta classe foi encontrada em maior quantidade ao longo do córrego Moeda, em sua foz (área de represamento da UHE Porto 
Primavera no rio Paraná) e em seus afluentes (córregos Querência e Granada). No córrego Buriti e nos outros afluentes temporários, não foi possível a identificação desta classe, devido aos canais serem estreitos e encoberto pelas matas ciliares e, em alguns casos, por encontrarse secos.

O Cerrado apontou uma área relativamente pequena em comparação ao tamanho da BHCM, apenas $1,44 \mathrm{~km}^{2}$, representando $3,42 \%$ e sendo encontradas em manchas dispersas ao longo das pastagens, sobretudo no alto curso e, em sua maior quantidade, nas proximidades dos recursos hídricos no alto e médio curso da bacia hidrográfica. Esta classe é caracterizada por árvores com galhos tortuosos e secos, que não permitem uma maior cobertura do solo contra a ação das águas pluviais e não possuem manejo da terra.

As áreas de Cerrado se encontram em sua grande maioria, em estágio de autoregeneração, entretanto, a BHCM vem sofrendo com degradações mesmo antes do plantio do eucalipto na década de 90 e toda a área foi deixada em pousio para autorregeneração, porém, devido ao passado de pecuária extensiva de corte, que acabou prejudicando todas as áreas florestais, bem como, alterou o equilíbrio deste ambiente, fez com que estas áreas não apresentem capacidade para se autorregenerar de forma rápida, sendo necessária que seja realizada uma recomposição, não só das matas ciliares, mas também destas áreas de cerrado, que possuem papel fundamental na estruturação deste sistema e seu imediato equilíbrio.

Com características próximas ao Cerrado, o Cerrado Úmido apresenta um solo diferente, pois é hidromórfico (terrenos úmidos ou alagados) e foram encontrados nas proximidades dos recursos hídricos, principalmente em áreas que não possuem mata ciliar, sobretudo, no alto e baixo curso, com exceção de uma área próxima a rodovia MS-395 no médio curso, abrangendo um total de $1,46 \mathrm{~km}^{2}$

A classe destinada ao Cultivo de Seringueira apresenta pequena área próxima a foz do córrego Moeda, sendo caracterizada por uma monocultura com desenvolvimento radicular e com curvas de nível, portanto, possui manejo (MHB) em suas terras, abrangendo $0,13 \mathrm{~km}^{2}$.

As Edificações existentes na BHCM compreenderam as sedes das fazendas e as áreas de construções e de propriedade da Fibria MS Celulose Ltda.; abrangendo pequenas áreas nas proximidades do ponto 10 (estação meteorológica) e da rodovia MS-395 (estação de gás e galpão para guardar caminhões), apontando para um total de $1,18 \mathrm{~km}^{2}$.

A classe de Solo Exposto é caracterizada pela falta de cobertura vegetal, conforme Figura 6, podendo ser encontradas em áreas de pastagens que perderam sua vegetação devido a falta de chuvas ou outro tipo de uso e principalmente, é encontrada nas áreas que serão utilizadas para cultivo de eucalipto. 
Figura 6: Alto curso da BHCM, área de solo exposto destinada ao cultivo de eucalipto pela Fibria-MS Celulose Ltda., na margem direita do córrego Moeda.

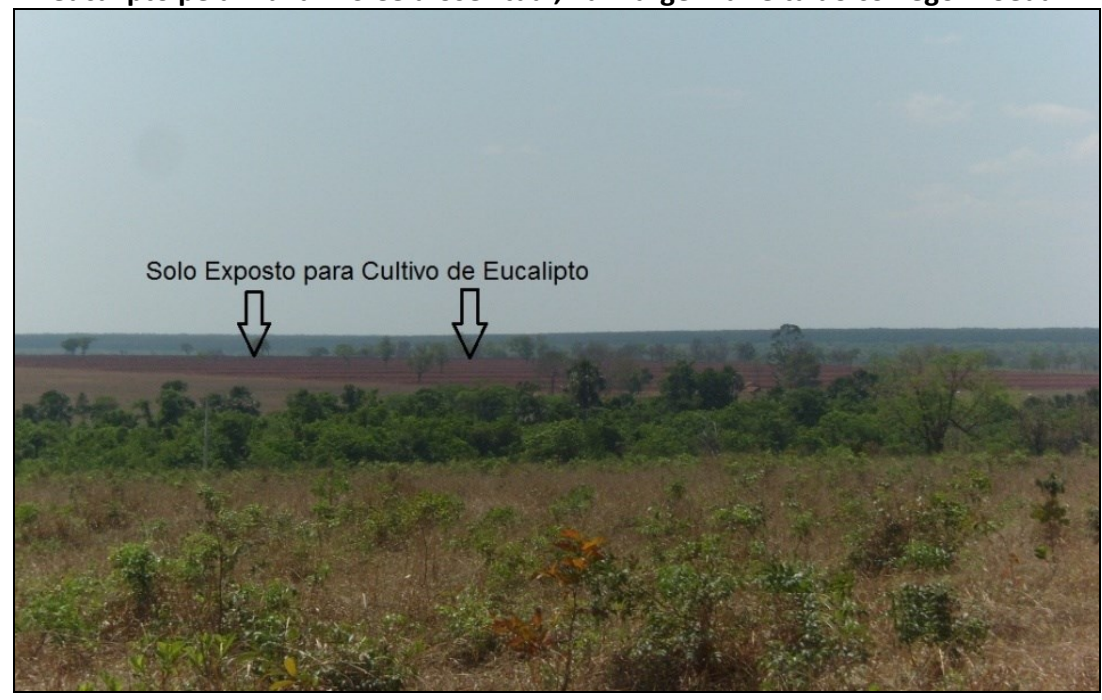

Dessa forma, esta classe abrangeu $13,01 \mathrm{~km}^{2}$, com suas terras encontradas em grande parte após a rodovia MS-395, no médio/baixo e baixo curso da BHCM, devido ao corte dos talhões de eucalipto que foram realizados de forma errônea, pois estes cortes foram realizados em uma estação que pela média, é chuvosa, sem contar que os talhões que apresentaram cortes, se encontram muito próximos uns aos outros, favorecendo a perda de grande quantidade de sedimentos, que acabam influenciando no ponto $10 \mathrm{e}$, sobretudo no ponto 11 que ficou constatada uma alta quantidade de sedimentos em suspensão nas águas superficiais do córrego Moeda.

A análise da velocidade de fluxo e vazão das águas superficiais foi realizada em todos os onze pontos de coleta das águas na BHCM. Sendo que os dados foram demonstrados na Tabela 2 e Figura 7, para que seja possível sua melhor visualização e interpretação das informações e no transporte de sedimentos em suspensão, a pesquisa oferece informações sobre a capacidade erosiva das vertentes, as quais são transportadas pelo canal fluvial, sofrendo influência clara da velocidade de fluxo e vazão das águas superficiais. A obtenção de valores maiores de velocidades e vazões, consequentemente o transporte de sedimentos em suspensão, será maior, levando-se em conta que estas variáveis possuem relação com o tipo de utilização e manejo da terra. 
Tabela 2: Análise de velocidade, vazão e transporte de sedimentos em suspensão na BHCM, Três Lagoas/MS.

\begin{tabular}{crrrrrrr}
\hline Pontos & $\begin{array}{c}\text { Velocidade } \\
(\mathbf{m} / \mathbf{s})\end{array}$ & \multicolumn{1}{c}{$\begin{array}{l}\text { Área } \\
\left(\mathbf{m}^{2}\right)\end{array}$} & $\begin{array}{c}\text { Vazão } \\
\left(\mathbf{m}^{\mathbf{3}} \mathbf{s} \mathbf{s}\right)\end{array}$ & $\begin{array}{c}\mathrm{g} / \mathbf{1 0 0} \\
\mathbf{m l}\end{array}$ & $\mathbf{g} / \mathbf{m}^{\mathbf{3}}$ & $\mathbf{g} / \mathbf{m}^{\mathbf{3} / \mathbf{s}}$ & Ton/Estação \\
\hline 1 & 0,00 & $*$ & & 0,0180 & 180,00 & $*$ & $*$ \\
2 & 1,55 & 0,01228 & 0,01903 & 0,0005 & 5,00 & 0,09 & 0,74 \\
3 & 2,75 & 0,00675 & 0,01856 & 0,0021 & 21,00 & 0,38 & 3,03 \\
4 & 2,60 & 0,01469 & 0,03819 & 0,0009 & 9,00 & 0,34 & 2,67 \\
5 & 7,20 & 0,03330 & 0,23976 & 0,0003 & 3,00 & 0,71 & 5,59 \\
6 & 5,20 & 0,06958 & 0,36182 & 0,0001 & 1,00 & 0,36 & 2,81 \\
7 & 5,20 & 0,26744 & 1,39069 & 0,0009 & 9,00 & 12,51 & 97,32 \\
8 & 1,10 & 0,02127 & 0,02340 & 0,0016 & 16,00 & 0,37 & 2,91 \\
9 & 5,40 & 0,16760 & 0,90504 & 0,0005 & 5,00 & 4,52 & 35,18 \\
10 & 14,20 & 0,11823 & 1,67887 & 0,0002 & 2,00 & 3,35 & 26,10 \\
11 & 8,90 & 0,61823 & 5,50225 & 0,0002 & 2,00 & 11,75 & 91,43 \\
\hline Média/Total & 5,41 & 0,13294 & 1,01776 & 0,0253 & 253,00 & 34,44 & 267,82 \\
\hline
\end{tabular}

* açude,ambiente lêntico.

Figura 7: Dados de vazão e transporte de sedimentos em suspensão na BHCM, Três Lagoas/MS.

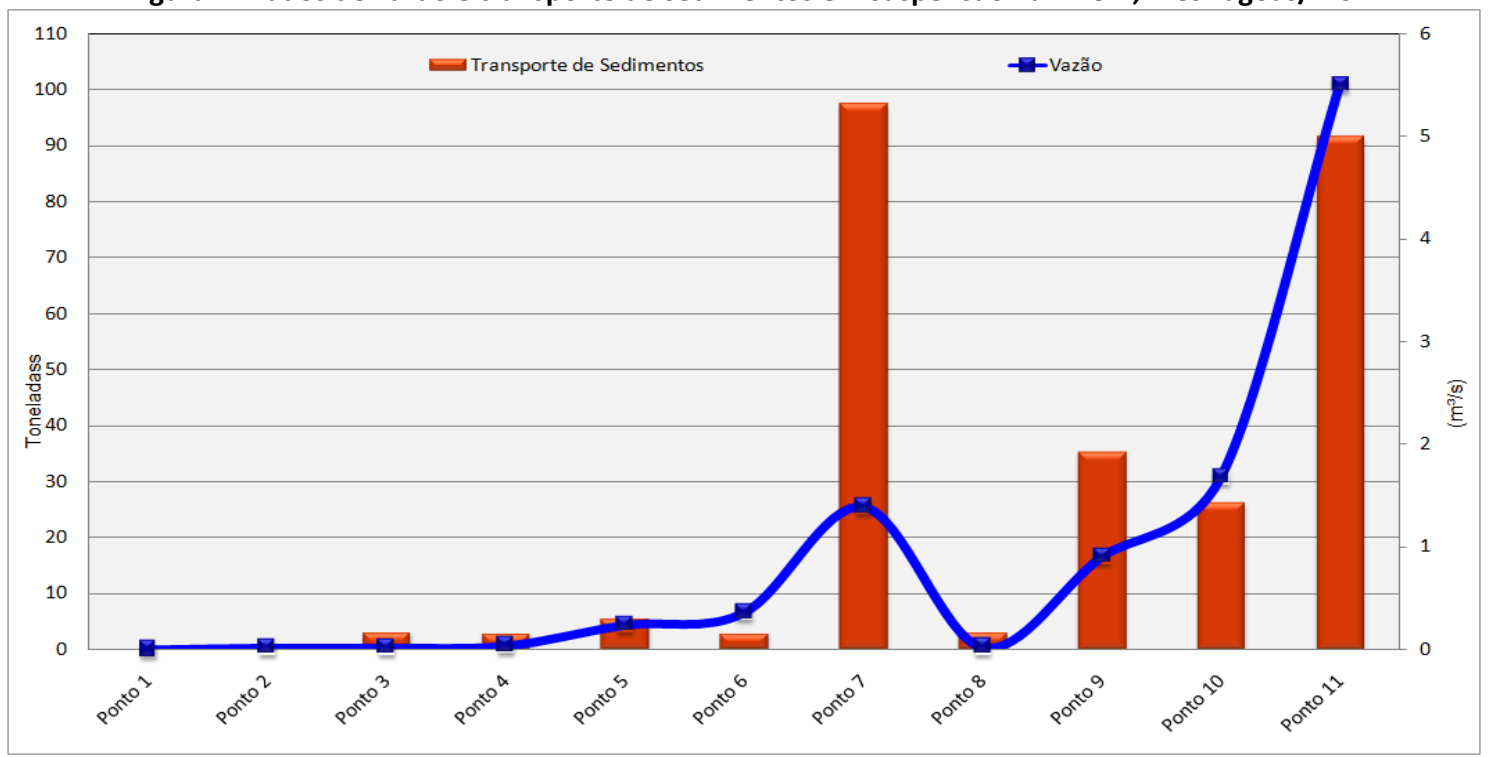

O ponto 10 obteve maior velocidade $(14,20 \mathrm{~m} / \mathrm{s})$ dentre todos os pontos analisados. Isto pode ter sido ocasionado por ser um ponto de pouca profundidade e seu leito fluvial é formado por grande quantidade de cascalho, além da declividade nesta área apresentar uma elevação chegando ao baixo curso do córrego Moeda. Entretanto, sua pouca profundidade fez com que não apresentasse a maior vazão.

Neste ponto, apesar de não possuir mata ciliar em parte de suas margens, sobretudo em sua margem esquerda, e de possuir valores elevados de vazão, não apresentou grandes valores de transporte de sedimentos, principalmente por essa sua característica de fundo, que diminui a subida de sedimentos em suspensão pelo turbilhonamento provocado pela velocidade e a rugosidade, contudo, é necessário destacar que tanto esse ponto, como o ponto 11, foram locais onde ocorrem grandes cortes de talhões, ocasionando em uma maior sedimentação das 
partes mais altas da bacia, ficando evidenciado no último ponto, que ocorreu a maior vazão e também o maior transporte de toda a BHCM.

Este ponto 11 apresentou menor velocidade que o ponto 10, porém, possui maior área transversal do canal e é mais profundo, elevando sua capacidade de transporte, que somado às grandes áreas de solo exposto nas proximidades, devido ao corte dos talhões de eucalipto, alcançando 91,43 toneladas de sedimentos em suspensão.

Outro ponto que possui destaque é o 7. É o local do córrego Moeda apresenta a maior profundidade alcançada, porém é mais estreito que o ponto 9, pois é um local onde o córrego se ramifica em três canais fluviais e neste local ocorre grande quantidade de deposição de sedimentos, somados a grande vazão deste ponto e a existência, na margem direita do canal, de antigo bebedouro para gado e seu uso ser predominante de pastagens sem curvas de nível, alcançando $5,20 \mathrm{~m} / \mathrm{s}$ de velocidade, sua vazão alcançou $1,39069 \mathrm{~m}^{3} / \mathrm{s}$, que acabou elevando os valores de transporte, chegando à 97,32 toneladas.

O Ponto 5 apresentou elevada velocidade $(7,20 \mathrm{~m} / \mathrm{s})$, principalmente por ser um local próximo a uma ponte, e a grande quantidade de caminhões e às chuvas ocasionaram o desmoronamento dos tubos de concreto. Como consequência, formaram-se pequenas quedas d'água que, por sua vez, elevam a velocidade deste ponto.

Do ponto 2 ao 6 não apresentou grandes valores no transporte de sedimentos, pois o canal fluvial possui pouca vazão, reduzindo seus valores e com relação ao ponto 1 (Figura 8), apresentou grande quantidade de sedimentos em suspensão, verificando-se $180,00 \mathrm{~g} / \mathrm{m}^{3}$, ou $70,5 \%$ mensurado em toda a bacia, principalmente pelo fato de servir de bebedouro de gado bovino, sem mata ripária, cercado por pastagens cultivadas sem curvas de nível, possibilitando que o gado paste dentro do açude, localizado no alto curso na fazenda Querência.

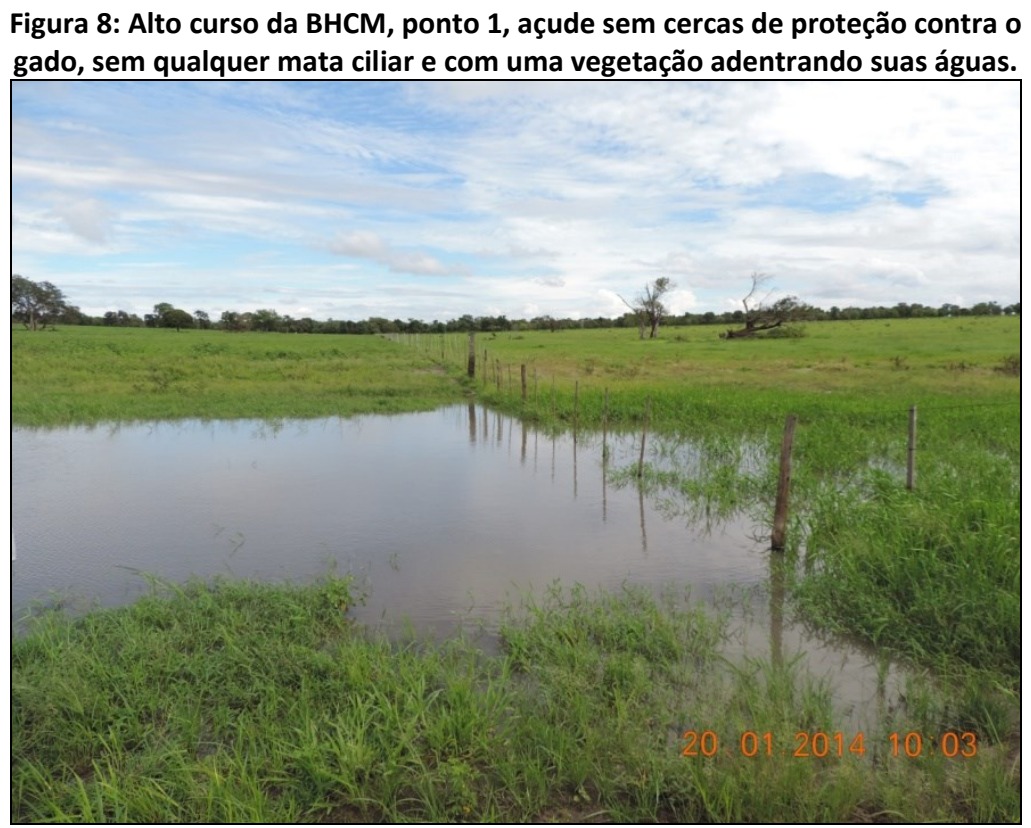


Todas estas informações correspondem ao reflexo da ação erosiva sobre as vertentes da BHCM. Juntamente da interação com o uso, cobertura e manejo da terra, acaba alterando todo o comportamento hidrossedimentológico dos canais fluviais desta bacia hidrográfica. Mesmo não ocorrendo grandes cortes de talhões, com exceção no Horto Dobrão, nas proximidades dos pontos 10 e 11, que, por não ter sido escalonado o corte, eleva a ação das águas correntes.

Desta forma, o monitoramento destas áreas, como também, o emprego de práticas conservacionistas são essenciais para manter o solo fértil, oferecendo ao mesmo, condições pra que se torne produtivo. Dentro destas práticas necessárias, sobretudo em áreas com grande quantidade de eucalipto em escala comercial, são necessários controles das ações erosivas, e um destes controles, é o corte escalonado dos talhões, que se mostrou como o mais preocupante para a quantidade das águas e seu transporte de sedimentos em suspensão. Com isso, o monitoramento se torna essencial, buscando aferir os elementos que compõe este sistema, retratando de que forma o ambiente está alterando e onde ele influencia de forma mais consistente.

\section{CONCLUSÃO}

Nesta pesquisa é realizada uma análise do que ocorre de perda de solo na BHCM, para isto, faz-se necessário o monitoramento da velocidade, vazão e transporte de sedimentos em suspensão ao longo dos onze pontos de coleta das águas, mostrando que as vazões e velocidades ao longo dos pontos se mostraram altas, isso ficou refletido no transporte de sedimentos em suspensão, que alcançou um total de 267,8251 toneladas. Com ênfase nos pontos 7, 9, 10 e 11, que apontaram as maiores vazões, velocidade e consequentemente, maior transporte de sedimentos em suspensão.

Outra área que merece destaque, é nas proximidades do ponto 1, por carrear grande quantidade de sedimentos, esta área merece uma relevância maior, por estar localizada nascente do córrego Moeda, em um açude sem qualquer tipo de proteção ou vegetação, sendo utilizado como bebedouro para o gado, cercado de uma pastagem sem qualquer tipo de manejo da terra, portanto há carência de práticas conservacionistas no uso destas terras, como por exemplo, a implantação das curvas de nível para a limitação do escoamento superficial.

Com estas problemáticas, é necessário levar em consideração que o controle da perda de solo, depende diretamente da cobertura dessa terra, seja com vegetações de raízes profundas, que retêm o solo impedindo que ocorra uma desagregação, ou por uma vegetação que recubra o solo contra o impacto direto das gotas de chuva sobre as partículas do solo, reduzindo as possíveis erosões e os escoamentos superficiais na área.

No uso, cobertura e manejo da terra são necessários apontar que as áreas de eucalipto da Fibria MS Celulose Ltda.; não adentram as matas ciliares, respeitando o que é exigido pelo Código Florestal. Isso se mostrou importante na análise, mas as grandes áreas de cerrado e matas ciliares encontram-se em sua grande maioria em estágio de regeneração, pelo fato da 
BHCM vir sofrendo com degradações antes mesmo do plantio do eucalipto na década de 90 , principalmente por pecuária extensiva de corte que derrubou as matas ciliares e prejudicou o equilíbrio deste ambiente. Sendo plantada "brachiara" até as margens dos córregos, levando todo seu alto curso a secar e os buritis existentes a morrerem, isto ainda se mostra preocupante nos pontos 1, 6, 7, 8, 9 e 10, onde as matas ciliares ainda apresentam falhas, indicando uma pastagem até as margens dos cursos fluviais, sendo que em todos estes não possuem cercas de proteção, mas apenas os pontos 1, 7 e 9 foram percebidos animais nas áreas.

O grande e principal problema enfrentado por este tipo de monocultura, com base nesta pesquisa, é com relação ao corte dos talhões em áreas extensas, por essa razão, cada horto é plantado com em media um ano de diferença, para sempre terem boa parte da BHCM com vegetação consistente e que proteja o solo.

Portanto, é necessária que a continuação do monitoramento dos recursos desta bacia hidrográfica seja constante, sobretudo em termos de quantidade das águas superficiais e no uso e cobertura da terra, adotando sempre que possível, um manejo conservacionista ao longo de toda a BHCM.

\section{REFERÊNCIAS BIBLIOGRÁFICAS}

CARVALHO, A.R.; SCHLITLER, F.H.M.; TORNISIELO, V.L. Relações da atividade agropecuária com parâmetros físicos químicos da água. Química Nova. São Paulo. v.23, n.5, p.618-624, 2000.

CHRISTOFOLETTI, A. Geomorfologia. São Paulo, Edgard Blücher, 2a edição, 1980.

ESRI 2011. ArcGIS Desktop: Release 10. Redlands, CA: Environmental Systems Research Institute.

FIBRIA/MS. 2014. Plano de Manejo: Unidade Florestal MS - Três Lagoas. 7ạ edição, 2014.

IBGE - Instituto Brasileiro de Geografia e Estatística. Cidades. Disponível em: <http://www.cidades.ibge.gov.br/xtras/home.php> Acesso em: Fev de 2015.

INTERNATIONAL PAPER. Estudo de impacto ambiental: fábrica de Três Lagoas. Três Lagoas: IP, 2006. 981 p.

PINTO, A. L.: MAURO, C. de; A importância do Ribeirão Claro para o Abastecimento de água da cidade de Rio ClaroSP. Geografia Teorética. Rio Claro, v. 15, 1985: p. 104-117.

PINTO, André L.; LORENZ SILVA, J. L.; FERREIRA, A. G.; BASSO, P. M. Subsidio Geológico/Geomorfológico ao ordenamento do uso, cobertura e manejo do solo, visando à redução da perda de solo e a recuperação da qualidade das águas superficiais da Bacia do Córrego Bom Jardim, Brasilândia/MS. Relatório Final FUNDECT/MS. UFMS. Três Lagoas, 2010: 147p.

PINTO, André L.; LORENZ SILVA, J. L.; FERREIRA, A. G.; BASSO, P. M. Subsidio Geológico/Geomorfológico ao ordenamento do uso, cobertura e manejo do solo, visando à redução da perda de solo e a recuperação da qualidade das águas superficiais da Bacia do Córrego Bom Jardim, Brasilândia/MS. Relatório Parcial FUNDECT/MS. UFMS. Três Lagoas, 2009: 42p.

REFLORE-MS. Associação Sul-Mato-Grossense de Produtores e Consumidores de Florestas Plantadas. Revista MS Florestal 2013. Disponível em: <http://www.reflore.com.br/dados/revista-ms-florestal-2013>. Acesso em: Janeiro de 2015. 
SPRING. Integrating remote sensing and GIS by object-oriented data modelling. Camara G, Souza RCM, Freitas UM, Garrido J Computers \& Graphics, 20: (3) 395-403, May-Jun 1996.

USGS - United States Geological Survey. Earth Explorer. Disponível em: <http://earthexplorer.usgs.gov>. Acesso em: 07 de Fevereiro, 2015. 